Title: AYUSH Research Portal: Matching Traditional Indian Knowledge with Modern Needs

Authors: Rakesh Sarwal, MBBS. DrPH ${ }^{1}$

T Saketh Ram, BAMS, MD, PhD²

${ }^{1}$ NITI (National Institution for Transforming India), New Delhi

${ }^{2}$ CCRAS- National Institute of Indian Medical Heritage, Hyderabad

${ }^{1}$ Corresponding author (sarwalr@gmail.com) 


\begin{abstract}
Indexing is a mandatory requirement for the sustenance and progress of any scientific discipline. AYUSH Research portal (https://ayushportal.nic.in/) is an exclusive portal meant for indexing and dissemination of research findings in the domain of Ayurveda, Yoga \& Naturopathy, Unani, Siddha, Sowa-Rigpa and Homeopathy and allied faculties. By 2010, despite the availability of up to 45 databases catering to Complimentary and Alternative medical systems (CAM), none was dedicated to index-based search on the literature of AYUSH systems. Though PubMed remained a very vast storehouse, limited indexation of AYUSH journals left searches incomplete. To address this problem a dedicated portal on AYUSH systems was developed with an exclusive focus on bringing research findings in a relatable, user-friendly manner by providing the contents based International Classification of Disease (ICD) - 10 terms and International Classification of Primary Care (ICPC) classification while at the same time preserving the ontological nuances of these systems. This fete over a decade has resulted in an impressive portal housing more than 30,000 articles with a very good reception among the scientific community. This article discusses the evolution of the concept and steps involved in the development and sustenance of this portal. We list out further steps required to develop the portal into a global treasure house.
\end{abstract}




\section{AYUSH Research Portal: Matching Traditional Indian Knowledge with Modern Needs}

Rakesh Sarwal, MBBS. DrPH' ${ }^{1}$ T Saketh Ram, BAMS, MD, PhD²

${ }^{1}$ NITI (National Institution for Transforming India), New Delhi

${ }^{2}$ CCRAS- National Institute of Indian Medical Heritage, Hyderabad

${ }^{1}$ Corresponding author (sarwalr@gmail.com)

\section{Introduction}

AYUSH Research portal (ARP) ${ }^{1}$, launched in May, 2011 is a one-stop portal promoted by the Government of India for storage, retrieval and dissemination of curated research findings (pre-clinical, clinical, fundamental and drugs) in Indian Systems of Medicine, namely Ayurveda, Yoga \& Naturopathy, Unani, Siddha, Sowa-Rigpa and also Homeopathy (called AYUSH) searchable by both AYUSH disease terminologies, and International Classification of Diseases (ICD) ${ }^{2}$ of modern medicine. ARP enables to show case research findings in an organized fashion, avoid duplication of work, encourage interdisciplinary research and generate evidence for wider acceptance world wide of traditional Indian Systems of Medicine. Ten years after its launch, the team behind ARP trace its origin, its development, current status and suggest the way forward.

\section{Need for development of AYUSH Research Portal}

The primary function of standard library cataloguing systems has been to classify knowledge into searchable units and making them available to the user through suitable indexing. Earliest databases on medicine began with "Medical Literature Analysis and Retrieval System (MEDLARS) at the "National Library of Medicine" to build one of the first major machine-readable databases and batch retrieval systems for bibliographical index back in $1960^{3}$.

With the advent of Information Technology, the efforts have moved from manual indexing to electronic databases, which are an integrated collection of logically related records or files consolidated into a common pool that provides data for multiple uses. The availability of PubMed $^{4}$ in 1996 allowed easy electronic search and retrieval of scientific journal articles related to medical science.

In 2010, 45 databases ${ }^{5}$ were identified as dealing with Complementary and Alternative Medical Systems (CAM) by Boem K et.al. Of these, only one active databases was from India that covered herbal therapies, while none was devoted to any of the AYUSH systems. Many researchers had highlighted the difficulty in conducting literature reviews in Ayurveda ${ }^{6} 7$. This was a gap, that needed to be addressed immediately to bring to the researchers worldwide the available knowledge in different systems of AYUSH, and to encourage collaborative work.

Further, it is pertinent to note that prior to 2010, published literature on AYUSH in electronic form was scanty, scattered with very limited open access. Most of the works were in hardbound print form, often locked in libraries and private collections and overtly guarded by copyright making it difficult for researchers 
and other stakeholders to access them or utilize the available knowledge for clinical application, research, or taking policy decisions. The situation relating to research articles was far more precarious. On the one hand, Research Councils in different AYUSH systems (Ayurveda, Yoga and Naturopathy, Unani and Siddha) did print in-house journals, these were not available in electronic form, or shared with sister research councils on any common platform for collaboration.

PubMed was already indexing many articles from AYUSH streams in journals indexed with it. But the limitation with PubMed was the few journals on Indian Systems of Medicine indexed with it. A large amount of already published literature in print remained out of PubMed's purview. For example a reputed Ayurveda journal "Aryavaidyan"8 published by Aryavaidyashala, Kottakkal was available only in print form and is not indexed in PubMed to date.

Further it is pertinent to note that most of the texts on AYUSH systems are from classical literature in original Sanskrit, Arabic, or Tamil. Besides, challenges of drug standardization, conduct of pre-clinical and clinical studies, safety cum efficacy studies for plant and mineral based formulations, yoga practices throw up unique challenges which require a customized presentation of research studies. No such facility to view unique dimensions of research in AYUSH systems was then available.

Standardization of therapies and treatments of traditional medicine are fundamental to their global acceptance. ${ }^{910}$ While considerable work in this area has been done, much remains to be done for AYUSH systems.

\section{Methods}

While designing ARP, our vision was to develop a portal which could showcase on a common platform literature, and research in any one AYUSH system to other systems, as also to the experts of the modern systems of medicine. This would help Research Councils, National Institutes under the department of AYUSH and researchers in general identify promising areas, be informed of the strength of other sister systems of medicine and conduct collaborative research.

In this regard, we drew inspiration from the efforts of the World Health Organization in coordination with Department of AYUSH to bring in essential elements for standardizing complementary and alternative systems. Some of such efforts were "Standardized terminologies for Ayurveda, Siddha and Unani"11 through W.H.O country office, India, development of benchmark documents etc. However, there was no tool to view AYUSH therapies and research findings by International family of Classifications of conditions, namely ICD-10 12 , or International Classification of Primary Care ${ }^{12}$.

The idea of creating a common electronic dashboard for indexing literature on different AYUSH systems offered a great opportunity to bring in all these systems, along with researchers in these domains, together and to work for a larger goal to find solutions for hard to treat conditions. Since this was 
happening for the first time, there was a lot of interest among the Research Councils, and support from the top management.

A brainstorming session followed with a few departmental organizations to develop a blueprint. Out of them, the National Institute of Indian Medical Heritage (NIIMH), Hyderabad of Central Council for Research in Ayurveda and Siddha (then) were assigned the task to plan for the proposed Ayurveda research database. The idea was examined and after due consultations with experts in other councils, a dash board was first designed to allow search by systems besides Ayurveda viz., Siddha, Unani, Yog \& Naturpathy, Homeopathy and Sowa-Rigpa. The idea was presented by the authors in late 2010 before the then Secretary, Mrs. S Jalaja, IAS, who immediately supported it and gave the green signal.

A crack team in the CCRAS was formed, under the leadership of Dr. Saketh Ram, which worked diligently at a neck break speed to develop the portal and hosted it on NIC, Hyderabad platform (https://ayushportal.nic.in/) within a short span of six months. The exceptional commitment of Dr. R. Rajasekaran, a Siddha Research officer of NIIMH is worth mentioning here. He was the main architect of software design, coded the entire application following a strict timeline. Unfortunately, he passed away few years later which was a great loss to the team, which carried his work forward.

After completion of the beta version of the portal a detailed presentation was made before Mr. Anil Kumar IAS, Secretary, Department of AYUSH (who succeeded Mrs. S. Jalaja) and with his approval the application was launched in May 2011 during the AYUSH retreat hosted for senior officials.

\section{Results: Key Features of AYUSH Research Portal}

Ayush Research Portal indexes ${ }^{4}$ articles in branches of AYUSH, rather than journals, that meet basic standards of quality of research. Rather than automatic inclusion of few articles from indexed journals, articles are selected based on their scientific merit. An assessment of research quality, and worthiness for inclusion is done by teams of experts drawn from respective AYUSH research councils. The work flow was designed in such a way that four Research Councils (Ayurveda, Yoga \& Naturopathy, Unani, Siddha), National institutes viz., Institute of Post Graduate Training, Research in Ayurveda (IPGT \& RA), Jamnagar, National Institute of Ayurveda, Jaipur, National Institute of Unani, Bangalore, National Institute of Homeopathy, Kolkata, National Institute of Naturopathy, Pune participated in populating and updating the data. They have exclusive credential based access to the system. Under the lead of each research council, editorial committees were constituted for maintaining high standards in selecting and presenting research material. This was also happening for the first time in the history of AYUSH wherein experts from different streams were working together on a common dashboard exhibiting great solidarity and synergy.

The criteria of inclusion of an article is that the topic is related to at least one of the AYUSH Systems of medicine. A unique feature of ARP is not the reputation or status of the Journal but the content of the article which after selection is put 
to a rigorous review by select editorial team. The article is indexed only after the editorial team is satisfied that it is suitable for inclusion. As of now 535 journals are indexed, from which articles pertaining to AYUSH are scrutinized and after vetting for suitability, are included in ARP.

Indexing of articles in ARP was done separately for Title of the article, name of the Author(s), Journal;s name, Institution / Department and the Abstract. A few journals are indexed, from which all articles were automatically included in ARP. Each indexed article is given a unique, six-digit Identity Number, clicking on which leads the viewer to the page displaying complete information, including its downloadable link and URL.

The architecture of ARP was so designed to enable cross discipline search for any medical condition. The portal was designed to display information under the following ten headings 1. Standard Treatment Guidelines 2. Preventive promotive health 3. Preclinical and Clinical Studies 4. Literary and Fundamental Research 5. Drug standardization 6. Local health traditions 7. Drug monographs 8. Formulary of India and other formularies 9. References from Classical text books and 10. Plant monographs.

The home page of ARP displays summary information on the total number of articles indexed for each medical system (totaling 31064 on 30.3.2021), and their further broken up into categories of clinical research (numbering 5561), pre-clinical research (numbering 12,925), drug research (numbering 7709) and fundamental research (numbering 4870).

The information provided is categorized as per individual AYUSH medical systems against standard set of Medical conditions, based on WHO disease classification ICD-1012, while navigation is provided as per 16 body systems in ICPC's (International Classification of Primary Care) ${ }^{13}$.

The Portal also allows advanced search using a string for any medical system by any category. Users can query the database for any AYUSH system, body system, disease condition using ICD code or perform a simple string based, boolean search. It is also possible to search by the name of the medical condition as per AYUSH systems, which further adds to ease of retrieval. On selection of the displayed results, the user gets information in the form of an abstract, and full text of the article, wherever openly available.

A vital value addition of the portal is categorization of clinical research work into Grade A, B and C based on "General Guidelines for methodologies on Research and Evaluation or Traditional medicine published by World Health Organization $(\mathrm{WHO})^{14}$. The grading allows the researchers and also policy makers to assess the current R\&D status of AYUSH and plan further studies to fill in the gaps.

ARP allows for Cataloging of Ayurvedic published books founded on Original Manuscripts and Extra-Mural Research Project Reports. Most viewed and downloaded articles, recently uploaded articles and even the number of users online at any point of time are displayed on the portal. 
The portal is available as an open access repository and visitors can provide valuable feed back through the stipulated email id "ayushportal-ccras@gov.in" to the team. By 30 st March 2021 the portal recorded 7,00,204 visitors 31064 articles with 484688 views, 90260 downloads.

Salient features of AYUSH Research Portal are

1. Bridging the language barrier by making content of publications in classical or local languages available in English and also by using standard medical terminologies. This ensures wider availability of AYUSH research findings for further exploration by researchers.

2. Contents are searchable by category (AYUSH Systems, By Disease Name etc.,)

3. Free flowing search (By key word/random word search)

4. Linkages with International Classification of Disease-10 and further stratification with the categories of ICPC for improving clinical relevance

5. Grading clinical research articles into A, B or C categories of evidence based on "General Guidelines for methodologies on Research and Evaluation or Traditional medicine" published by World Health Organization (WHO)

6. Unique collection from legacy print version of articles to electronic versions available recently.

7. Expert driven (in terms of sourcing articles, vetting and indexing)

8. Application Hosted on secure Government Cloud (NIC) with redundancy and security built-in.

9. Publicly funded and open access

Another portal named Digital Helpline for Ayurveda Research Articles, DHARA ${ }^{7}$ was developed in 2012. DHARA provides a free indexing service for papers published in research journals in the field of Ayurveda. Like ARP, DHARA provides a powerful search tool to track research articles in Ayurveda. The AYUSH Research Portal and DHARA, both have been promoted and funded by Ministry of AYUSH A comparison of the scope of PubMed, DHARA and ARP is presented in the Table. 
Table: PubMed, DHARA Portal and AYUSH Research Portal

\begin{tabular}{|c|c|c|c|}
\hline Feature(s) & PubMed & DHARA Portal & AYUSH Research Portal \\
\hline $\begin{array}{l}\text { Scope of } \\
\text { indexing }\end{array}$ & $\begin{array}{l}\text { Articles of medical } \\
\text { importance (Animal/Plant } \\
\text { etc.,) }\end{array}$ & $\begin{array}{l}\text { Ayurvedic articles } \\
\text { only }\end{array}$ & $\begin{array}{l}\text { Ayurveda, Yoga \& } \\
\text { Naturopathy, Unani, Siddha, } \\
\text { Sowa-Rigpa and Homeopathy, } \\
\text { (AYUSH) }\end{array}$ \\
\hline $\begin{array}{l}\text { Number of } \\
\text { Journals } \\
\text { covered }\end{array}$ & $\begin{array}{l}\text { Ayurveda-3 } \\
\text { Yoga - } 3 \\
\text { Naturopathy }-1 \\
\text { Complimentary Medicine } \\
-4 \\
\text { All - } 11\end{array}$ & 902 & $\begin{array}{l}535, \text { and as and when an } \\
\text { article pertaining to AYUSH is } \\
\text { published in a journal other } \\
\text { than these enlisted, it is } \\
\text { considered for inclusion based } \\
\text { on merits through editorial } \\
\text { vetting. }\end{array}$ \\
\hline $\begin{array}{l}\text { Clinical } \\
\text { Article } \\
\text { grading } \\
\text { policy }\end{array}$ & No grading is provided & $\begin{array}{l}\text { No grading is } \\
\text { provided }\end{array}$ & $\begin{array}{l}\text { Grading clinical research } \\
\text { articles into A,B,C grades } \\
\text { based on "General Guidelines } \\
\text { for methodologies on } \\
\text { Research and Evaluation or } \\
\text { Traditional medicine" } \\
\text { published by World Health } \\
\text { Organization (WHO }\end{array}$ \\
\hline Search & $\begin{array}{l}\text { Free Flowing; Advance } \\
\text { search }\end{array}$ & Free flowing & $\begin{array}{l}\text { Free flowing and by AYUSH } \\
\text { Category }\end{array}$ \\
\hline $\begin{array}{l}\text { Number of } \\
\text { AYUSH } \\
\text { Related } \\
\text { articles }\end{array}$ & $\begin{array}{l}\text { Ayurveda- } 6109 \\
\text { Siddha- } 430 \\
\text { Unani- } 657 \\
\text { Yoga- } 6049 \\
\text { Naturopathy- } \\
\text { 1400 } \\
\text { Homoeopathy- } 6060 \\
\text { Sowa-Rigpa-21 } \\
\text { Total: 20726 }\end{array}$ & $\begin{array}{l}\text { Ayurveda- } 2654 \\
\text { (Dhara articles with } \\
\text { key word "Ayurveda") }\end{array}$ & $\begin{array}{l}\text { Ayurveda- } 22769 \\
\text { Siddha- } 1772 \\
\text { Unani- } 2632 \\
\text { Yoga \& Naturopathy- } 1424 \\
\text { Homeopathy- } 2467 \\
\text { Sowa-Rigpa-Nil } \\
\text { Total: } 31064\end{array}$ \\
\hline
\end{tabular}

The above table illustrates that by far for AYUSH Systems AYUSH research portal hosts highest number of articles, which is further likely to increase in due course of time.

\section{Discussion}

The success of AYUSH Portal has served as a proof of the concept of intersystem dialogue within the medical fraternity. Further it has set up an example of working relationship within existing standard frameworks viz., International Classification of Diseases by WHO and ICPC, which in a way laid the foundation of the idea of dual coding. Dual coding is a standard practice of assigning traditional medicine diagnostic code along with relevant ICD-10/11 code based on specific epistemologies. This is widely practiced as a policy of medical case recording by Chinese(9) and Korean governments since last many decades. The innovation in Ayush Research Portal facilitated later developments such as launch of National AYUSH Morbidity and Standardized terminologies electronic (NAMASTE) $^{11}$ portal (2017), AYUSH hospital information management system $(\text { AHMIS) })^{15}$ in 2018 and collaborative projects with W.H.O for drafting ICD-11 codes. The ARP currently serves as a host of a dedicated 'National Repository on AYUSH COVID 19 Clinical and other R\&D Initiatives' which gives an insight to Research works in AYUSH on COVID 19. This is a phenomenal trajectory of 
events in Ministry of AYUSH (then department), which are worthy of due recognition and appreciation.

\section{Conclusion, way forward}

The ARP is yet to incorporate some standard references viz. from classical text books. Besides, the Portal can include standard references, like Standard Treatment Guidelines, local health traditions, Drug monographs, plant monographs, Formulary of India and other formularies. These were a part of original plan for bringing in completeness of this portal and for it to serve as a single window for authentic information on Research, policy framework and reference materials for AYUSH systems.

The Portal has had highest contributions from Ayurveda, followed by Siddha system. Other AYUSH systems need to gear up to include more articles and update the contents. On the technological front launch of mobile app is a logical extension to cater to the tastes of the current generation. ARP and DHARA could be integrated at the back end to form a single, large database on Ayurveda literature. Further Doctoral and Post Graduate dissertations uploaded on SHODHGANGA can be considered for inclusion in ARP.

Finally, the momentum has to sustained and AYUSH portal should aim to become a world renowned, standard repository like the PUBMED. It could aspire to add Traditional and Complimentary System related information globally which is presently not indexed or captured by PubMed. 
Author Contributions

RS conceived of, designed the paper and refined the drafts. SR wrote the first draft and helped improve it. RS was posted as Joint Secretary in the Department of AYUSH between November, 2010 to July, 2011.

Financial/non-financial disclosures

No financial assistance was obtained from any source for writing this paper. As stated in the text, ARP was fully funded by the Department of AYUSH, Government of India.

\section{Acknowledgments}

We sincerely thank the support from the team of Central Council for Research in Ayurvedic Sciences (CCRAS) during the year 2020-Dr. Rameshbabu, former Director General, Dr. M.M. Padhi, former Deputy Director (Technical), Dr. N. Srikanth, DDG, CCRAS (2016-), Dr. Ala Narayana, Director, National Institute of Indian Medical Heritage, Hyderabad, Dr. R. Rajasekaran, Research Officer (Siddha), Dr. B. Venkateshwalu, Research Officer Ayurveda, NIIMH, Hyderabad. Our thanks to Vd. Prof. K.S. Dhiman, Director General, CCRAS, Dr. P.V.V. Prasad, Asst. Director, NIIMH, Hyderabad for sustaining momentum and continuing the patronage to the portal. Sincere thanks to all contributors, editors and ground staff from then Department of AYUSH, Other research Councils viz., Central Council for research in Unani Medicine (CCRUM), Central Council for Research in Homeopathy $(\mathrm{CCRH})$, Central Council for Research in Yoga \& Naturopathy and all National Institutes. Special thanks to current Secretary, Vaid Rajesh Kotecha for helpful comments on the draft version. 


\section{References}

1.MoAYUSH: AYUSH Research Portal. 2021. Available from: https://ayushportal.nic.in/ 2. Madden R, Sykes C, Ustun TB and others: World Health Organization family of international classifications: definition, scope and purpose. Geneva: World Health Organization. 2007. Available from: https://www.who.int/classifications/en/FamilyDocument2007.pdf?ua=1 3.NIH: PubMed Overview. 2021. Available from: https://pubmed.ncbi.nlm.nih.gov/about/ 4.Dhammi I and UI-Haq R: What is indexing. Indian Journal of Orthopaedics. 2016;50:115. DOI: 10.4103/0019-5413.177579

5.Boehm K, Raak C, Vollmar HC and Ostermann T: An overview of 45 published database resources for complementary and alternative medicine. Health Information $\{\mid \&\}$ Libraries Journal. 2010;27:93-105. DOI: 10.1111/j.1471-1842.2010.00888.x

6.Narahari SR, Aggithaya MG and Suraj KR: Conducting literature searches on Ayurveda in PubMed, Indian, and other databases. The Journal of Alternative and Complementary Medicine. 2010;16:1225-1237.

7. Manohar P, Eranezhath S, Mahapatra A and Manohar S: DHARA: Digital Helpline for Ayurveda Research Articles. Journal of Ayurveda and Integrative Medicine. 2012;3:97. DOI: 10.4103/09759476.96530

8.Sala AV: Aryavaidyan. 2021. Available from:

https://www.worldcat.org/title/aryavaidyan/oclc/20697862

9. Wang J, Guo Y and Li GL: Current Status of Standardization of Traditional Chinese Medicine in China. Evidence-Based Complementary and Alternative Medicine. 2016;2016:1-7. DOI:

$10.1155 / 2016 / 9123103$

10.Chaudhary A and Singh N: Contribution of world health organization in the global acceptance of ayurveda. Journal of Ayurveda and Integrative Medicine. 2011;2:179. DOI: 10.4103/0975-9476.90769

11.MoAYUSH: National AYUSH Morbidity and Standardized Terminologies Portal (NAMASTE PORTAL). 2021. Available from: http://namstp.ayush.gov.in/\#/index

12.Bramer GR: International statistical classification of diseases and related health problems. Tenth revision. World health statistics quarterly. Rapport trimestriel de statistiques sanitaires mondiales. 1988;41:32-36.

13.WONCO: International Classification of Primary Care. 2021. Available from:

https://www.globalfamilydoctor.com/site/DefaultSite/filesystem/documents/Groups/WICC/ International Classification of Primary Care Dec16.pdf

14.WHO: General guidelines for methodologies on research and evaluation of traditional medicine. 2000. Available from:

https://apps.who.int/iris/bitstream/handle/10665/66783/WHO_EDM_TRM_2000.1.pdf?

sequence $=1$ \&isAllowed $=y$

15.MoAYUSH: AYUSH HOSPITAL MANAGEMENT INFORMATION SYSTEM. 2021. Available from: http://ehr.ayush.gov.in/ayush/ 